\title{
The Third Equilibrium: The Economic Impact of Future and the Model of Multidimensional Equilibrium
}

\author{
Xiaohuang Zhu, Wei Sun, Xin Cai \\ Shenzhen Mongoose Consulting Co., Ltd, Shenzhen, China \\ Email: Ydjh_Mgs@163.com
}

How to cite this paper: Zhu, X. H., Sun, W., \& Cai, X. (2021). The Third Equilibrium: The Economic Impact of Future and the Model of Multidimensional Equilibrium. Theoretical Economics Letters, 11, 21-46. https://doi.org/10.4236/tel.2021.111002

Received: May 31, 2020

Accepted: January 5, 2021

Published: January 8, 2021

Copyright $\odot 2021$ by author(s) and Scientific Research Publishing Inc. This work is licensed under the Creative Commons Attribution International License (CC BY 4.0).

http://creativecommons.org/licenses/by/4.0/

\section{(c) (i) Open Access}

\begin{abstract}
Based on the consideration of the impact of current and local economic activities on the future and whole society, this paper takes factors such as time, space, opportunity and equity into analysis framework, and establishes a new equilibrium system-multidimensional equilibrium. Then, combining the theory of multidimensional equilibrium and revenue-cost analysis, a multidimensional equilibrium model is constructed. This model provides a tool for evaluating the social and economic activities more intuitive and scientific. Finally, in order to verify the effectiveness and universality of the multidimensional equilibrium theory and model, this paper selects three representative examples of economic activities from the macro level, the medium level and the micro level respectively, and applies the multidimensional equilibrium theory to evaluate the economic activities at different levels through the actual data. This study shows that, considering the future total revenue and total cost of economic activities from the dimension of time and space, with time goes on, most of the social total revenue of economic activities and the ratio of total cost increase after decreasing first. This tells that in the short-term future, the total revenue of some economic activities may be greater than the total cost, while in the long-term future, the total revenue is less than the total cost. Therefore, from the perspective of the long-term development, the development planning of a country should give more consideration to the multidimensional equilibrium, especially taking account of the future risks.
\end{abstract}

\section{Keywords}

Multidimensional Equilibrium, Inflection Point, Space-Time Dimension, Total Cost, Total Revenue 


\section{Introduction}

Uncertainty and symmetry are two fundamental properties of the world. Economics should handle the relationship between fairness and efficiency from these two perspectives. In the vast analytical framework of economics, equilibrium theory is the most important branch. In macroeconomics and microeconomics, equilibrium is not only a way of thinking and theoretical framework, but also a guide for organizing economic activities, allocating economic resources and evaluating economic structure.

Traditionally, after more than 200 years of development, the two best known achievements of modern economics in equilibrium theory are General Equilibrium and Nash Equilibrium. General equilibrium theory is a branch of theoretical microeconomics, which seeks to explain production, consumption and price within the framework of the overall economy. General equilibrium refers to the existence of such a price system in the economy, which enables each consumer to provide his own production factors at a given price, and to maximize his consumption utility by purchasing products under his own budget constraints. Each enterprise will determine its output and demand for production factors under a given price to maximize its profits, each market (product market and factor market) will reach the equilibrium between total supply and total demand in this price system.

Nash equilibrium is an important term of game theory. In the process of a game, no matter what the strategy choice of the other party, one party will choose a certain strategy, which is called the dominant strategy. The combination is defined as Nash equilibrium if any player chooses the optimal strategy when all other participants' strategies are determined.

According to the principle of equilibrium, we studied and developed a series of reports and articles on inflection points from 2015 to 2019, and the technology and principle of risk measurement were applied in our studies. The main function of them is to predict the basic future trends of various economic activities including possible revenues and risk costs in the future. Published reports include $A$ study on the inflection point of China's debt $t^{1}$ Equity index construction and Research on wealth gap ${ }^{2}, A$ Study on the Early Warning Index System for China's Systemic Risk, Urban Development Inflection point, Enterprise Scale and Governance Structure Inflection point, Golden Ratio of China's Real Economy and Virtual Economy. All of them point to the future.

So, what exactly will the future do to the present? In what way? However, when standing in the future and ask questions of the present, we feel that the analytical framework of economics still lacks some tools. As we all know, the General equilibrium solves the optimal equilibrium problem of resources allocation in the market under specific conditions, and the Nash equilibrium provides

\footnotetext{
" A study on the inflection point of China's debt" had been published in Springer nature in 2018. "Equity index construction and Research on wealth gap" had been published in Palgrave Macmillan in 2019.
} 
the optimal scheme for game of psychological behavior in economic activities, then we discuss a new equilibrium problem in this paper-Economic fluctuations make the future have a great impact on the present. How can the current economic behavior achieve a new equilibrium with the consideration of the future? What we called it the Third equilibrium. It means to take time and space as the main dimension to study and analyze economic problems, quantifying factors, such as uncertainty and fluctuation, risk cost and opportunity cost, social fairness into variable combinations and incorporating them into the economic analysis framework. As this study fully considered the changes and influences of the above factors in time and space, we reset the equilibrium relationship, which is called Multidimensional Equilibrium. This paper attempts to propose a logical approach and a modeling tool to solve this problem. This paper is expected to be a revolutionary one.

\section{From Equilibrium Theory to Multidimensional Equilibrium Theory}

\subsection{The Evolution of Symmetry Uncertainty and the Idea of Equilibrium}

Symmetry is a highly evolved law of nature, otherwise the tendency to transfer risk to the weak and innocent will not be contained. Furthermore, consequences of risk transfer will not only lead to the extinction of the weak and innocent, but also lead to the collapse of the whole natural system. In the same way, all legal rules and morality advocating fairness and justice in human society emphasize the principle of symmetry. However, the uncertainty of knowledge, especially the uncertainty of information, leads to a great deal of asymmetry in human activities affairs, in which the phenomena of transferring risks to irrelevant subjects in different spaces and transferring risks to the future are typical examples. It can be concluded acceptable that to some extent, human science, including economics, is an attempt to compensate for asymmetry or to correct imbalance, that is, to pursue equilibrium.

Equilibrium point is a relative certainty expression of uncertainty. When the economy $\mathrm{p}$ is in equilibrium, it often indicates the realization of a certain symmetry and a certain new trend. However, this equilibrium is hard to be sustained. That's to say, symmetry is more easily replaced by asymmetry, and the equilibrium point can easily become an inflection point indicating a change in trend. Yet, the idea of equilibrium can be deeply explored. The present concept and structure of equilibrium theory cannot explain all economic phenomena. From this point of view, in order to explore the new connotation of equilibrium concept and find the ideological foundation of the new equilibrium for resources allocation and the analysis of the rationality of economic behavior, this paper starts from the in-depth exploration of the deeper connotation of the idea of equilibrium, tracing the evolution process of equilibrium. 


\subsection{The Evolution of Equilibrium Thought}

Adam Smith described the uncertain nature of economic activity by the invisible hand. And it was he who first introduced the idea of equilibrium into economic analysis. This became the distinction between classical economics and the old economic theory, which is also a sign of the age of science (Murray \& Stimson, 1996; Smith, 2003). But Smith's point was not in the equilibrium field. He discussed equilibrium in some his famous theory works, and thought it was the center of gravity of an economic system, which represents the original classical concept of equilibrium. But it was John Stuart Mill's formal discourse on political economy that really spread the word. This is when studies opened a new chapter of neoclassical equilibrium (Mill, 2004).

The innovation of neoclassical equilibrium is to expand the equilibrium into general equilibrium and local equilibrium. Both of them actually contain core contents of Marshall, which said that supply and demand are equal and the market is clearing. The difference between the two lies in the difference of research scope and method (Marshall, 2006). However, the neoclassical equilibrium is still essentially static (Henry, 1983). Fundamentally, the reason why the neoclassical equilibrium model is difficult to deal with dynamic problems is that the interdependence of variables in this model cannot be described by the causal relationship in past time. This defect makes it difficult for the idea of equilibrium to be improved in the neoclassical framework. And this work was carried on Keynesianism.

Keynes' idea of equilibrium broke the tie of classicism and neoclassicism to the staticness, objectivity, and absoluteness of equilibrium. His idea of equilibrium consists of two levels. Firstly, the intermediate equilibrium and the regularity of finite fluctuation. Secondly, the moving equilibrium, and the consistency of the short-term equilibrium and the long-term equilibrium. Finite volatility means that equilibrium can be relative, moving equilibrium means that equilibrium can be dynamic. And the emphasis on expectations of long-term and short-term equilibrium means that equilibrium can be subjective. To some extent Keynes overturned the neoclassical view of equilibrium. However, the efforts to integrate Keynesian equilibrium and neoclassical equilibrium into classical equilibrium came from the theoretical contributions of the non-Walras equilibrium school.

\subsection{The Theory of Equilibrium Analysis}

Equilibrium analysis plays an important role in economics. Generally, equilibrium can be divided into local equilibrium and general equilibrium. In 1874, with his work Pure Economic Essence, French economist Leon Walras established the theory of general equilibrium. He proposed that under perfect competition, the total income from the sale of all factors of production must equal the total income from the sale of all consumer goods (Walras, 1989). 
John von Neumann, one of the founders of game theory, believed that, there is always a maximum and minimum equilibrium in a two-person zero-sum game (Neumann \& Morgenstern, 1994). However, for the zero-sum game, its application value in social science is limited. Later, Nash put forward the standard of dividing cooperative game and non-cooperative game in 1950-1953. He proved the existence of strategic equilibrium in non-cooperative game. Since then, Nash equilibrium has become an important concept in management and economic analysis (Nash, 1950a, 1950b, 1951, 1953).

The Nash equilibrium is based on the assumption that people are mercenary, but it loses the demand for equity under the specific humanistic environment, which obviously cannot explain the essence of all economic phenomena. The hypothesis of general equilibrium is established under the condition of relative certainty. And it seems that it cannot give comprehensive explanation about the economic operation mechanism under the condition of uncertainty.

\subsection{The Multidimensional Equilibrium}

By reviewing equilibrium theory related literatures, we find that the concept of equilibrium theory and denotation can be expanded further. Objectively, the rationality of evaluating the current economic activities is not limited to the current economic utility, its impact on the future should be taken into consideration either. In other words, it is necessary to predict the changes in revenues and losses caused by future fluctuations and incorporate them into the current economic analysis. Therefore, in the study of equilibrium theory, the past, the present and the future should be regarded as a unified and consistent process. And this makes the complete rigorous research logic. Uncertainty determines the nature of economic activity across time and space. In view of this, we need to incorporate the time dimension and the space dimension into the equilibrium system. The time dimension mainly refers to the uncertainty and fluctuation on the time curve, while the space dimension mainly refers to the opportunity cost under the space change, and the fair scale is a comprehensive consideration of the time and space dimensions. In addition to the analysis under certain conditions, dynamic analysis should consider the economic equilibrium between different time and space. The process of perfecting equilibrium theory is not a process of replacing the old with the new, but a process of explaining different economic phenomena in different theoretical frameworks under different conditions.

So far, we can conclude the defects of the present equilibrium theory and thoughts. First of all, although it is confirmed that all economic activities exist in the form of fluctuations under the premise of economic uncertainty, the quantitative relationship of such fluctuations to revenues and costs has not been seriously considered. This fluctuating process includes the past, present and future. It has been well considered in the models of general equilibrium and Nash equilibrium. However, such variables as the future and the future fair opportunity cost of return risk due to fluctuations have not been fully considered. 
In terms of equilibrium theory, after introducing the element of future with many economic variables, it actually raises the problem of new equilibrium conditions and algorithms. This urges us to improve and supplement the equilibrium theory theoretically. To sum up, on the basis of general equilibrium and Nash equilibrium, a third kind of equilibrium concept, method, tool and a set of ideological system are established. We call this new equilibrium a multidimensional equilibrium. The formation and framework of multidimensional equilibrium will be discussed later.

\section{The Development of Multidimensional Equilibrium Theory}

\subsection{The Principle of Economic Uncertainty}

Modern economic can be regarded as a game process of psychology and behavior, and a social activity with uncertainty as the condition. The management of this uncertainty is the process of risk management, the concept of risk management in economics refers to the uncertainty of economic subjects about the distribution and status of future economic conditions (especially gains and losses). The data can only be used to express the current situation and future to some extent, and the closest calculation results are found through econometric models and tools to guide people's understanding of the current situation and prediction of the future.

Uncertainty can be divided into measurable and non-measurable, and the risk management theory is to study and calculate the phenomenon of measurable uncertainty. In economics, Knight distinguished risk from uncertainty for the first time. Knight says measurable uncertainty is risk, and that's how you manage it. If everything is measurable, in a perfectly competitive market, entrepreneurs cannot profit. Knight's answer is that profits come from the unpredictable, from the uncertain, like the wind that blows a leaf, there are always a few surprises. Therefore, uncertainty is the source of benefits.

\subsection{Risk Management and the Mongoose Inflection Point}

The most important thing of risk management is to grasp the turning point of the development of things, that is, the inflection point. Mongoose think tank has been engaged in the research of inflection point, and based on this, it forecasts and warns the future. We named the inflection point which reflects the future situation as the Mongoose inflection point, which is different from the inflection point in general mathematics and econometrics. Therefore, we hope to use the concept of Mongoose inflection point to express the uncertainty, and use the method of risk measurement to predict the future trend from a new perspective of economic observation, and form a new system of economic research. The logical order is that, because of the uncertainty, the risk is objective and measurable. All things in the world have the development law of coexistence of positive and negative effects, that is, the existence of paradox. Once the balance be- 
tween total income and total loss of economic things is broken, economic things will develop along a certain trend and reach a new equilibrium. On behalf of the turning point of a new trend, there is an inflection point of economic development, that is, a certain point on the mathematical curve. In economics, we can use this turning point to warn some future development trends.

\subsection{From the Mongoose Inflection Point to the Multidimensional Equilibrium}

The process of looking for inflection points of things is measuring the relationship between returns and risks, and determining an optimal inflection point. After the inflection point, the risk cost will be more and more than the risk return, and the nature of things will change. This is the main idea expressed by Mongoose inflection point. Therefore, the inflection point is an outlook of future uncertainty and the early warning of risks. The study of inflection point is a special study of the uncertainty of things, which is not only a profound economic problem, but also a sociological problem, and also a prediction of the future risk cost.

The Mongoose inflection point theory holds that there are both benefits and losses, and factors have positive and negative effects. At the inflection point, the relationship between positive and negative factors should be studied simultaneously. It is a law and a trap, implying that short-term good can be long-term bad. Statistical analysis is easy to fall into this trap, and the inflection point analysis should consider the future risk loss, which is beneficial to avoid this trap.

Therefore, starting from the Mongoose inflection point, when we look at risks from the perspective of the future and the macro-economy as a whole, we find that the risks brought by future uncertainty and fluctuations not only form the risk cost in risk management, but also bring the economic problems of fairness and efficiency and ethical evaluation. So, the existing equilibrium theory is only limited to the study of the inflection point of ordinary mathematics or econometric category, and the research of Mongoose inflection point needs the help of new equilibrium theory-Multidimensional Equilibrium Theory. The multidimensional equilibrium is not limited to the symmetry of benefits and risks in the sense of traditional risk management, and it includes the opportunity cost of spatial dimension and the fair scale of comprehensive consideration of time and space dimension.

\section{The Theoretical Framework of Multidimensional Equilibrium}

\subsection{Multidimensional Equilibrium Is the Economic Application of Risk Principle}

As to upgrade the risk principle into a theory and an analysis tool that can be used in economics, the main purpose is to bring the income and loss variables in the four factors of opportunity and equity into the economic analysis frame- 
work.

From the risk principle, there are four types of problems to be prevented in economic behavior.

Firstly, risk moves backward in the time dimension. Risk costs are left for the future, and these costs are calculated as the current benefits to obtain corporate profits or personal compensation. Possible future losses in time dimension should be an important variable in current economic analysis. Secondly, risks transfer in space area. If the development of a land is at the cost of the loss of $b$ land, it is a shift of risk from place to place, which will produce an unfair development result at the cost of the corresponding opportunity cost. Therefore, the opportunity loss and risk growth in the surrounding areas should also become important mathematical variables of multidimensional equilibrium. Thirdly, the methods of risk concealment and bearer transfer lead to the unfair consequences of the current economy. It is also a serious information asymmetry that the economic entity USES various immoral methods to conceal the possible future losses, which will make the current development or exchange show results and gains to encroach on the future results and gains. Such as heavily polluting investment or over-development, over speed development can lead to a violation of intergenerational equity. Therefore, the occurrence probability and loss rate of all kinds of non-deontological techniques are also important multidimensional equilibrium variables. Fourthly, opportunity cost is ignored. The complete investment cost should include financial cost, opportunity cost and risk cost. In modern management accounting, opportunity cost is an important program comparison reference, but it is not really included in the current cost. Therefore, the gains and losses brought by opportunity investment should be an important variable of multidimensional equilibrium.

\subsection{The Multidimensional Equilibrium Is the Perfection of Sustainable Development Theory}

There are two basic problems that economics has to solve: one is growth, and the other is equity. Then how to solve the equity problem? The third equilibrium theory from the perspective of the future for the current transaction to solve the problem of equity any transaction or investment in the current period should be established on the basis of the principle framework of multidimensional equilibrium, is reasonable. In the analysis system of economics, there are many theories that take the future as an important dimension, which is represented by the theory of sustainable development (Wang, 2018).

As the most obvious sustainable development problem, intergenerational impartiality aims to solve the equity in the time dimension. Intergenerational impartiality is the strategic thinking of the concept of sustainable development in terms of resource allocation to make fair use of natural resources between different generations. First, each generation has the right to preserve and choose its natural and cultural diversity. It is incumbent on contemporary people to pre- 
serve natural and cultural resources for future generations. Second, every generation has the right to health and a decent quality of life. Third, contemporary decision-making should reflect the principle of fairness that no generation is dominant in the allocation of resources. The present generation must leave behind a livable earth and environment for future generations, and should also pay off the natural debts left by the past.

But future generations do not have any right to contemporary affairs. The realization of this concept can only be made by the rules of contemporary human civilization and the empirical study. For economics, the proposal of this principle has not completely solved the problem, and there are still obvious imperfections. First is to focus too much on the future, ignoring the actual relationship between the future and the present. Second, the excessive emphasis on vertical time ignores the fairness of horizontal space. Most importantly, the theory of sustainable development is based on the direction of macro, emphasis on the concept. The logic system of sustainable development theory still lacks some economic theory foundation, which is that the correctness of sustainable development theory also needs the rationality of economic resource allocation principle to prove.

The multidimensional equilibrium theory integrates the future gains and losses into the current analysis framework of economic resource allocation, finally makes the correct concept of intergenerational equity based on the economic theory that can be realized and observed, and solves the underlying logic problem of sustainable development theory. This is a great theoretical improvement and harvest. The conflicts between environmental protection, pollution and development are also solved by the theory of multidimensional equilibrium.

\subsection{Theoretical Connotation of Multidimensional Equilibrium}

Multidimensional equilibrium, which is known as the third kind of equilibrium, starting from the demand of paradox resolution of risk principle and dynamic analysis, multidimensional equilibrium study starts from the essence of volatility, and expands fair scale of uncertainty, volatility risk cost and opportunity cost in two dimensions of time and space. In this framework our variables, including current revenues, costs, inputs and out puts, are obviously in equilibrium. It represents the equilibrium point between the development and risk of a social thing or economic phenomenon in multidimensional space and time. In other words, under the premise of full of uncertainty, multidimensional equilibrium is dedicated to the theoretical elaboration of a certain equilibrium state and inflection point in economic operation and the use of data model to measure it, so as to sublimate the existing economic resource allocation scheme, correct people's economic behavior in the current period and warn the trend of economic development.

As the most basic theory in economics, equilibrium has been paid much at- 
tention in many fields. However, because both general equilibrium and Nash equilibrium have not fully considered the fluctuation of uncertain returns and losses in the dimension of time and space as well as the influence of equity and opportunity factors on the equilibrium state, the multidimensional equilibrium to some extent makes up for the defects of the current equilibrium theory.

The theoretical connotation of multidimensional equilibrium can be expressed in the following theoretical categories.

1) The past, the present and the future make up the whole of time.

2) Everything has explicit revenues, implicit revenues, explicit costs and implicit costs. And the equilibrium between them is the condition of its economic attribute.

3) The development of things, especially the development of economy, is often a paradoxical process.

4) Fairness is a balanced relationship between human and nature, between human and the future.

\section{Multidimensional Equilibrium}

\subsection{The Algorithm of Multidimensional Equilibrium}

The algorithm idea of multidimensional equilibrium can be summarized as: from the risk principle, consider the relationship between the total amount of economic activity and the total amount of cost. On the basis of the econometric model, variables such as time dimension, space dimension, and substitution of profit and loss fluctuation risk cost, opportunity cost, and fair scale and so on are introduced, and appropriate open source data that can reflect the above dimensions and variables are selected to be substituted into the model for measurement. The resulting results are the actual values of multidimensional equilibrium.

In the framework design and risk measurement of the multidimensional equilibrium model, we choose the bank economic capital model as the foundation. When we try to introduce variables such as time-space dimension and volatility opportunity risk equity into a function, this function should be the basic model that reflects the relationship between the present and the future. The more logical algorithm is based on the function relation of risk measurement principle, which is the characteristic of economic capital measurement.

\subsection{Mathematical Model of Multidimensional Equilibrium}

Through the above analysis, the multidimensional equilibrium model mainly considers the relationship between total income and total loss of economic activities. This theory provides a method for the analysis and evaluation of the relationship between the gains and losses of social and economic activities. By using this method to evaluate economic activities, the possible results of certain economic behaviors can be reflected more intuitively and scientifically, so as to pro- 
vide a basis for decision makers to implement their economic activities. Therefore, the revenue-loss analysis method of multidimensional equilibrium can be widely applied to the evaluation and analysis of various investment or expenditure behaviors, which is not only applicable to the macro government public decision-making problem, but also to the micro project investment decision-making problem.

In order to facilitate the modeling and data accounting, we make the following assumptions and explanations. 1) Bank economic capital model, this paper thought the concept of expected loss and unexpected loss, profit and loss in cyber equilibrium theory can be divided into explicit and implicit part, including dominant gains or losses associated with a particular economic activity mainly refers to direct revenue or expenditure, implicit revenues and losses mainly refers to the external benefit from the economic activity and consumption; 2) This paper mainly accounts for the implicit revenues and losses from the dimension of space and time, that is, considering the future revenues and losses brought by current economic activities from the dimension of time, and considering the gains and losses brought by economic activities to the whole space (all regions of the society) from the dimension of space; 3) Considering the availability and quantification of the data, this paper cannot exhaust all the factors. Therefore, on the basis of the symmetry of the balance between gains and losses, the indexes that can reflect the gains and losses of economic activities to a large extent are selected; 4) This paper does not consider the theoretical revenues that are difficult to measure, such as residents' happiness satisfaction or pressure feeling; 5) Since the influence of economic activities is long-term, this paper divides the implicit income into the current implicit income and the future implicit income, and also divides the implicit loss into the current implicit loss and the future implicit loss; 6) The current recessive loss mainly refers to the loss of resources, ecological environment and other aspects caused by the current economic activities, while the impact of the current recessive loss on the future forms the future recessive loss of the current economic activities. Therefore, the paper assumes that the future recessive loss will fluctuate on the basis of the current recessive loss; 7) Future implicit income mainly refers to the contribution of current economic activities to future economic growth, but due to the existence of asset depreciation, this paper will be the current implicit income times the depreciation rate and then discounted back to the current value as the future implicit income.

In a word, the theory of multidimensional equilibrium takes the past, the present and the future as a unified economic process. When considering the benefits and losses of economic activities, it takes the relevant factors of fluctuations into account, which makes the evaluation of economic activities more perfect. Therefore, based on the above assumptions and explanations, this paper can construct an economic activity evaluation model based on the revenue-loss ratio under the theory of multidimensional equilibrium, as shown below. 


$$
\begin{aligned}
\text { revenue loss ratio } & =\frac{\text { revenues of economic activity }}{\text { costs of economic activity }} \\
& =\frac{\text { explicit revenues }+ \text { implicit revenues }}{\text { explicit costs }+ \text { implicit costs }} \\
\varepsilon=\frac{R}{\mathrm{C}} & =\frac{R_{d}+R_{I}}{C_{d}+C_{I}}=\frac{R_{d}+R_{0}+D P R}{C_{d}+C_{0}+D P C}
\end{aligned}
$$

$R$ and $C$ respectively represent the total revenue and total loss of economic activities, and $R_{d}$ and $R_{I}$ respectively represent the explicit revenue and implicit revenue of economic activities, $R_{0}$ represents current implicit revenues, $D P R$ represents present value of future implicit revenues. $C_{d}$ and $C_{I}$ respectively represent the explicit costs and implicit costs of economic activities, $C_{0}$ represents current implicit costs, $D P C$ represents present value of future implicit costs. In particular, for future implicit revenues or costs, this paper assumes that it is a random variable satisfying a certain distribution. If there is historical data, the distribution function can be fitted by historical data.

\section{Application of Multidimensional Equilibrium Theory}

\subsection{Political Term Impartiality}

How to achieve political term impartiality so that the governance or management of the appointee is properly constrained and motivated? Multidimensional equilibrium fills the gap in thinking about political term impartiality (Xiao \& Duan, 2008). Term impartiality is a dilemma of moral choice and a theoretical problem of economic behavior. How to achieve fair term so that the governance or management of the appointee is properly constrained? For different social subjects, how long the term of office is reasonable, which requires more in-depth empirical research, and only on the basis of the theory of heterogeneous equilibrium can such in-depth research have a feasible channel (Geng \& Pang, 2016).

The length of term affects not only the performance and stability of leadership, but also the broader revenues and costs. It is very common for enterprise executives or senior government officials to adopt aggressive operation and governance methods during their term. The essence of them is to shift or shift the risk loss of the current period and cash the future revenues in advance (such as tax collection in advance). Although the short-term revenues are positive, the positive effects are not long-term and many negative effects follow behind the boom. As to the economy, for example, there is too much leverage, too much overcapacity, too many inefficient and polluting enterprises, and too little capacity for scientific and technological innovation (Pang \& Wang, 2016). That is, the behavior of the government to allocate and use the actual economic resources and administrative resources during the term of office should be established on the basis of multidimensional equilibrium. It should not only consider the explicit social revenues and costs during the term of office, but also consider the implicit social revenues and costs in the long-term future. 


\subsubsection{Accounting Scope of Total Social Revenue and Total Social Cost}

Before the analysis of total social revenues and total social costs, we should make clear the basic contents and accounting scope of total social revenue and total social cost. We argue that the total social benefit refers to the wealth and economic progress created by the government for the local government in a certain period, as well as the contribution of economic activities in this period to the future economic growth. The total social cost refers to the management and investment in the political, economic, cultural and social development, and the human, material, financial and social resources that the government must expend in order to perform its functions and achieve its governing goals within a certain period of time, and the additional burden and loss resulted from it today and in the future. The specific accounting scope of both is as follows.

1) Accounting of total social revenue

In this paper, the total social revenue is divided into explicit revenue and implicit revenue, in which implicit revenue includes current implicit revenue and future implicit revenue. Explicit income represents the direct wealth income of the society, which can be measured by the fiscal revenue of the government. Implicit income represents the government's contribution to social and economic development, that is, social and economic progress. It can be measured by the increase of GDP brought about by economic activities in the current year. One thing to note is that, as current economic activities will create revenues for the society in the coming years, we divide them into current implicit revenues and future implicit revenues, where current implicit revenues refer to increment of GDP according to the current economic activity, and the future implicit revenues refer to the sum of GDP growth according to the future economic activity.

2) Accounting of total social cost

The total social cost is divided into explicit cost and implicit cost, in which implicit cost includes current implicit cost and future implicit cost.

Explicit cost represents the direct cost of social consumption, as measured by the fiscal expenditure of the government.

The implicit loss includes the cost of resources, ecological environment and people's livelihood.

In the calculation of resource cost, only the cost of representative land resources and mineral resources is calculated.

In the accounting of ecological environment loss, it mainly calculates the environmental economic content in a broad sense, that is, the loss of each part of the ecological environment. However, due to the limitation of a series of conditions such as the data accounting method, the ecological environment cost accounting can only be simplified. We focus on the accounting of environmental loss in the accounting of environmental loss, only accounting for environmental pollution, not the cost of ecological damage. The virtual treatment cost is used to calculate the environmental pollution. The virtual treatment cost refers to the expenditure needed to treat all the pollutants discharged into the environment 
according to the current treatment technology and level. It includes the actual quantity and value quantity of air pollution and water pollution and solid waste pollution, as well as the comprehensive accounting of both. This paper adopts the governance cost method to calculate the virtual governance cost, the specific idea of this method is: Assuming that all pollutants are treated, the environmental degradation will not occur in that year. Numerically, the virtual treatment cost is a lower limit of the environmental degradation value. In terms of accounting data, the emission of pollutants is selected as the actual amount of environmental pollution accounting data, and the treatment cost of pollutants is selected as the accounting data of environmental pollution value, that is, it is assumed that all the discharged pollution is treated.

In the accounting of the cost of people's livelihood, it mainly calculates the total increase of the living cost of local residents, including the cost of daily life, education, medical treatment and housing.

Future implicit cost mainly refers to the risks that the government's current actions may cause to the future. Since future costs are largely affected by current decisions, we assume that the future implicit cost in year $\mathrm{t}$ will fluctuate on the basis of current implicit cost.

\subsubsection{Model Specification}

Based on the idea of multidimensional equilibrium, the mathematical model of the ratio of total social revenue to total social cost for the term decision problem can be constructed as follows.

$$
\begin{aligned}
& \text { the ratio of total social revenue to total social cost } \\
& =\frac{\text { total social revenue }}{\text { total social revenue }} \\
& =\frac{\text { explicit revenue }+ \text { implicit revenue }}{\text { explicit cost }+ \text { implicit cost }} \\
& \varepsilon \varepsilon=\frac{\text { Revenue }}{\text { Cost }}=\frac{R_{d}+R_{I}}{C_{d}+C_{I}} \\
& \varepsilon=\frac{R}{\mathrm{C}}=\frac{R_{d}+R_{0}+\sum_{i=1}^{t} \frac{R_{0} * \alpha^{i}}{(1+\beta)^{i}}}{C_{d}+C_{0}+\sum_{i=1}^{t} \frac{C_{0}}{(1+\beta)^{i}}}
\end{aligned}
$$

The main symbols and descriptions used in this paper are as follows.

$R_{d}$ is the social explicit revenue; $R_{I}$ is the social implicit revenue; $R_{0}$ is the social current recessive cost; $C_{\mathrm{d}}$ is the social explicit cost; $C_{0}$ is the social current recessive cost; $\frac{R_{0} * \alpha^{i}}{(1+\beta)^{i}}$ is the future $i$ year of social implicit revenue discounted to the current value, $\sum_{i=1}^{t} \frac{R_{0} * \alpha^{i}}{(1+\beta)^{i}}$ is the future $t$ years of social implicit revenue 
and discounted to the current value; similarly, $\frac{C_{0}}{(1+\beta)^{i}}$ represents the value of the social implicit cost discounted to the current period in the future $i$ year, $\sum_{i=1}^{t} \frac{C_{0}}{(1+\beta)^{i}}$ represents the sum of the social hidden cost in the future $t$ year discounted to the current value, where a represents the social depreciation rate and $\beta$ represents the discount rate.

\subsubsection{Data Analysis}

In order to further explain the term decision model mentioned above, this paper takes X city of China as an example to carry out a case analysis to verify the effect of the model in practical application. It should be noted that most of the data in this paper are from the National Statistical Yearbook, and a small part of the data are from some research reports or papers.

1) Total social revenue of $X$ City

Based on the model setup and problem description, we collect the main economic indicators of $\mathrm{X}$ city in recent years, as shown in Table 1.

According to the accounting rules of total social revenue and total cost in the part 6.1.1, the explicit income represents the direct wealth income of the society, which can be measured by the fiscal revenue of the government. Thus, the fiscal revenue in Table 1 is explicit income of X city in recent years, as shown in Table 2.

According to the description in the previous accounting range, it can be seen that the economic activities in the current period will not only have an impact on the current economic growth, but also on the economic growth in the coming years. For clarity, let's define a new variable LGDP, which don't take into account the current year's economic activity, and assume that:

Table 1. Major economic indicators of X City in recent years (Unit: 100 million yuan).

\begin{tabular}{ccccc}
\hline Year & financial expenditure & fiscal revenue & GDP & fixed asset investment \\
\hline 2011 & 658.68 & 566.00 & 6615.60 & 3502.50 \\
2012 & 765.98 & 670 & 7424.32 & 4153.91 \\
2013 & 1014.23 & 788.93 & 8147.32 & 5027.86 \\
2014 & 1074.71 & 895.25 & 8850.54 & 5766.03 \\
2015 & 1222.87 & 1006.32 & 9472.4 & 6555.67 \\
2016 & 1352.85 & 1100.03 & $10,184.7$ & 7454.70 \\
2017 & 1403.03 & 1157.24 & $11,024.11$ & 7777.09 \\
2018 & 1561.23 & 1231.91 & $12,001.52$ & 8391.48 \\
\hline
\end{tabular}

Table 2. Explicit revenue of X City in recent years (Unit: 100 million yuan).

\begin{tabular}{ccccccc}
\hline Year & 2013 & 2014 & 2015 & 2016 & 2017 & 2018 \\
\hline Explicit Revenue & 788.93 & 895.25 & 1006.32 & 1100.03 & 1157.24 & 1231.91 \\
\hline
\end{tabular}




$$
L G D P=G D P_{l y} *\left(1+\alpha_{l y}\right) *(1-\eta)
$$

where $\alpha_{l y}$ represents growth rate of GDP in last year, $\eta$ represents depreciation rate. Therefore, the current year's implicit revenue should be the current year's GDP minus LGDP. According to the national statistical yearbook, the GDP growth rates of $\mathrm{X}$ city from 2012 to 2018 are $10.4 \%, 9.74 \%, 8.63 \%, 7.03 \%, 7.52 \%$, $8.24 \%, 8.87 \%$. In addition, by consulting literatures, the depreciation rate of the whole society $\eta$ is generally taken as 0.075 . So, put the GDP, GDP growth rates and e depreciation rate of X city from 2012 to 2018 into the formula (2), the LGDP of X city these years can be obtained. Then the implicit revenue of X City in recent years can be calculated by subtracting LGDP from GDP, as shown in Table 3.

The future implicit revenue of the current year is the effect of the current year's economic activity on the future years, which is then discounted to the current value. But there is depreciation of assets, so the impact of economic activity this year on the future will gradually diminish. As shown in Table 4, when discount rate are $8 \%$ and $7.5 \%$ respectively, we can get the future implicit revenue of X City in each year.

As shown in Table 5, combing with results in Tables 2-4, we can get the total social revenue of X City in the case of future implicit revenue in different years.

2) Total social cost of X City

According to the calculation above, total social cost includes explicit cost,

Table 3. Current implicit revenue in recent years of X City (Unit: 100 million yuan).

\begin{tabular}{ccccccc}
\hline Year & 2013 & 2014 & 2015 & 2016 & 2017 & 2018 \\
\hline GDP & 8147.32 & 8850.54 & 9472.40 & $10,184.70$ & $11,024.11$ & $12,001.52$ \\
LGDP & 7580.78 & 8270.17 & 8893.37 & 9377.61 & $10,129.27$ & $11,037.75$ \\
implicit revenue & 566.54 & 580.37 & 579.03 & 807.09 & 894.84 & 963.77 \\
\hline
\end{tabular}

Table 4. Future implicit revenue in recent years of X City (Unit: 100 million yuan).

\begin{tabular}{ccccccc}
\hline Year & 2013 & 2014 & 2015 & 2016 & 2017 & 2018 \\
\hline 1 year forward & 485.23 & 497.07 & 495.93 & 691.26 & 766.41 & 825.45 \\
2 years forward & 900.83 & 922.81 & 920.68 & 1283.31 & 1422.83 & 1532.43 \\
3 years forward & 1256.77 & 1287.44 & 1284.47 & 1790.39 & 1985.04 & 2137.95 \\
4 years forward & 1561.64 & 1599.74 & 1596.05 & 2224.70 & 2466.57 & 2656.57 \\
5 years forward & 1822.75 & 1867.22 & 1862.91 & 2596.67 & 2878.98 & 3100.75 \\
6 years forward & 2046.38 & 2096.32 & 2091.48 & 2915.26 & 3232.21 & 3481.19 \\
7 years forward & 2237.92 & 2292.53 & 2287.24 & 3188.13 & 3534.74 & 3807.02 \\
8 years forward & 2401.97 & 2460.58 & 2454.90 & 3421.83 & 3793.85 & 4086.10 \\
9 years forward & 2542.48 & 2604.52 & 2598.50 & 3622.00 & 4015.78 & 4325.12 \\
\hline 10 years forward & 2662.82 & 2727.79 & 2721.50 & 3793.43 & 4205.85 & 4529.83 \\
\hline
\end{tabular}


implicit cost in the current period and implicit cost in the future. Explicit cost can be obtained according to the financial expenditure in Table 1, while implicit cost in the current period includes resource cost, ecological environment cost and social livelihood cost. The resources cost mainly refers to the cost of land resources and mineral resources. In this paper, the newly constructed area of $\mathrm{X}$ City in the current year is used to represent the cost of land resources in current period. According to relevant literatures, the land resource value of $\mathrm{X}$ city mainly includes two aspects. One is the ecological value of the land; the other is the value of crops on the land. According to Littman's study, the ecological value and economic value of land is about 20 yuan per square meter. By consulting the land use area of $\mathrm{X}$ city in these years, we can get the loss of land resources in recent years, as shown in Table 6 below.

In terms of the consumption of mineral resources, since the mineral resources consumed by $\mathrm{X}$ city are mainly coal resources, this paper takes the consumption of coal resources as the mineral resources consumption of $\mathrm{X}$ city. We use the depletion value of natural resources to represent the cost of mineral resources. According to relevant literature, the cost per unit of standard coal is 11.4 yuan per ton. Therefore, combined with the coal consumption of $\mathrm{X}$ city in these years, the mineral resource loss in recent years can be obtained, as shown in Table 7 below.

Table 5. Total social revenue in recent years of X City (Unit: 100 million yuan).

\begin{tabular}{ccccccc}
\hline Year & 2013 & 2014 & 2015 & 2016 & 2017 & 2018 \\
\hline 0 year forward & 1355.47 & 1475.62 & 1585.35 & 1907.12 & 2052.08 & 2195.68 \\
1 year forward & 1840.71 & 1972.69 & 2081.27 & 2598.38 & 2818.49 & 3021.13 \\
\hline years forward & 2256.30 & 2398.42 & 2506.02 & 3190.44 & 3474.91 & 3728.11 \\
3 years forward & 2612.25 & 2763.06 & 2869.82 & 3697.52 & 4037.12 & 4333.63 \\
4 years forward & 2917.11 & 3075.36 & 3181.40 & 4131.82 & 4518.64 & 4852.25 \\
5 years forward & 3178.22 & 3342.84 & 3448.26 & 4503.80 & 4931.06 & 5296.43 \\
6 years forward & 3401.86 & 3571.93 & 3676.82 & 4822.39 & 5284.29 & 5676.87 \\
7 years forward & 3593.40 & 3768.15 & 3872.58 & 5095.25 & 5586.82 & 6002.70 \\
8 years forward & 3757.45 & 3936.20 & 4040.25 & 5328.96 & 5845.93 & 6281.78 \\
9 years forward & 3897.95 & 4080.13 & 4183.85 & 5529.12 & 6067.86 & 6520.80 \\
\hline 10 years forward & 4018.29 & 4203.41 & 4306.84 & 5700.56 & 6257.93 & 6725.51 \\
\hline
\end{tabular}

Table 6. Statistics of land resource cost in X City (Unit: 100 million yuan).

\begin{tabular}{ccccccc}
\hline Year & 2013 & 2014 & 2015 & 2016 & 2017 & 2018 \\
\hline land resource cost & 19.00 & 4.22 & 15.14 & 6.58 & 7.82 & 15.34 \\
\hline
\end{tabular}

Table 7. Coal resources cost in X City (Unit: 100 million yuan).

\begin{tabular}{ccccccc}
\hline Year & 2013 & 2014 & 2015 & 2016 & 2017 & 2018 \\
\hline coal resources cost & 1.86 & 1.70 & 1.69 & 1.69 & 1.70 & 1.70 \\
\hline
\end{tabular}


The resource cost in each year and current period of $\mathrm{X}$ city is given above, and then the ecological environment cost in the current period of X city is analyzed. Based on the relevant research on social cost, we select the treatment cost of "three wastes" as the ecological environment cost of the city. According to relevant literature, the average treatment cost of the "three wastes" in X city is 2 yuan per ton of waste water, 1200 yuan per ton of waste gas and 50 yuan per ton of waste material. Combined with the, the ecological environment costs of $\mathrm{X}$ city in recent years are shown in Table 8.

In view of the social livelihood cost, we use the total increase of living cost of all residents in the region to measure. According to the statistical data, the per capita consumption cost and population number of residents in $\mathrm{X}$ city in recent years are shown in Table 9. And people's living cost of $\mathrm{X}$ city in recent years is shown in Table 10.

We can get the current implicit costs of city $\mathrm{X}$ in recent years based on results in Table 6, Table 7, Table 8 and Table 10.

Based on data analysis and model setup, according to formula $\frac{C_{0}}{(1+\beta)^{i}}$ and discount rate, $8 \%$, we can get the expected future implicit costs of $\mathrm{X}$ city in recent years as in Table 12 .

As shown in Table 13, the total social cost of X city can be obtained by combining the financial expenditure data in Table 1, Table 11 and Table 12.

\subsubsection{Results Analysis}

According to Table 5 and Table 13, we can calculate the comparison of total

Table 8. Statistics of ecological environment costs in X City (Unit: 100 million yuan).

\begin{tabular}{ccccccc}
\hline Year & 2013 & 2014 & 2015 & 2016 & 2017 & 2018 \\
\hline ecological environment cost & 261.67 & 256.66 & 271.30 & 336.67 & 350.79 & 429.48 \\
\hline
\end{tabular}

Table 9. Statistics of living cost in X City.

\begin{tabular}{ccccccc}
\hline Year & $\mathbf{2 0 1 3}$ & $\mathbf{2 0 1 4}$ & $\mathbf{2 0 1 5}$ & $\mathbf{2 0 1 6}$ & $\mathbf{2 0 1 7}$ & $\mathbf{2 0 1 8}$ \\
\hline Per capita cost of living (yuan) & 18,470 & 19,653 & 21,326 & 23,256 & 25,232 & 27,316 \\
incremental cost (yuan) & 1625 & 1183 & 1673 & 1930 & 1976 & 2084 \\
$\begin{array}{c}\text { Population (Ten thousand) } \\
\text { (16) }\end{array}$ & 896.41 & 904.62 & 909.7 & 920.4 & 929.05 & 939.48 \\
\hline
\end{tabular}

Table 10. Statistics of social livelihood cost in X City (Unit: 100 million yuan).

\begin{tabular}{ccccccc}
\hline Year & 2013 & 2014 & 2015 & 2016 & 2017 & 2018 \\
\hline social livelihood cost & 152.59 & 111.08 & 157.09 & 181.23 & 185.55 & 195.69 \\
\hline
\end{tabular}

Table 11. Statistics of current implicit costs in X City (Unit: 100 million yuan).

\begin{tabular}{ccccccc}
\hline Year & 2013 & 2014 & 2015 & 2016 & 2017 & 2018 \\
\hline Current implicit cost & 434.55 & 438.63 & 445.67 & 602.43 & 634.14 & 670.96 \\
\hline
\end{tabular}


Table 12. Future implicit costs in X City (Unit: 100 million yuan).

\begin{tabular}{ccccccc}
\hline Year & 2013 & 2014 & 2015 & 2016 & 2017 & 2018 \\
\hline 1 year forward & 402.36 & 406.14 & 412.66 & 557.81 & 587.17 & 621.26 \\
2 years forward & 774.92 & 782.19 & 794.75 & 1074.29 & 1130.84 & 1196.50 \\
3 years forward & 1119.88 & 1130.39 & 1148.53 & 1552.52 & 1634.24 & 1729.13 \\
4 years forward & 1439.28 & 1452.80 & 1476.12 & 1995.32 & 2100.35 & 2222.30 \\
5 years forward & 1735.03 & 1751.32 & 1779.43 & 2405.33 & 2531.94 & 2678.95 \\
6 years forward & 2008.87 & 2027.73 & 2060.28 & 2784.96 & 2931.55 & 3101.77 \\
7 years forward & 2262.43 & 2283.67 & 2320.32 & 3136.47 & 3301.57 & 3493.27 \\
8 years forward & 2497.20 & 2520.65 & 2561.10 & 3461.95 & 3644.17 & 3855.76 \\
9 years forward & 2714.59 & 2740.07 & 2784.05 & 3763.31 & 3961.40 & 4191.41 \\
10 years forward & 2915.87 & 2943.24 & 2990.48 & 4042.35 & 4255.13 & 4502.20 \\
\hline
\end{tabular}

Table 13. Total social cost of X City in recent years (Unit: 100 million yuan).

\begin{tabular}{ccccccc}
\hline Year & 2013 & 2014 & 2015 & 2016 & 2017 & 2018 \\
\hline 0 year forward & 1448.78 & 1513.34 & 1668.54 & 1955.28 & 2037.17 & 2232.19 \\
1 year forward & 1851.14 & 1919.48 & 2081.20 & 2513.09 & 2624.34 & 2853.45 \\
2 years forward & 2223.70 & 2295.53 & 2463.29 & 3029.57 & 3168.01 & 3428.69 \\
3 years forward & 2568.66 & 2643.73 & 2817.07 & 3507.80 & 3671.41 & 3961.32 \\
4 years forward & 2888.06 & 2966.14 & 3144.66 & 3950.60 & 4137.52 & 4454.49 \\
5 years forward & 3183.81 & 3264.66 & 3447.97 & 4360.61 & 4569.11 & 4911.14 \\
6 years forward & 3457.65 & 3541.07 & 3728.82 & 4740.24 & 4968.72 & 5333.96 \\
7 years forward & 3711.21 & 3797.01 & 3988.86 & 5091.75 & 5338.74 & 5725.46 \\
8 years forward & 3945.98 & 4033.99 & 4229.64 & 5417.23 & 5681.34 & 6087.95 \\
9 years forward & 4163.37 & 4253.41 & 4452.59 & 5718.59 & 5998.57 & 6423.60 \\
10 years forward & 4364.65 & 4456.58 & 4659.02 & 5997.63 & 6292.30 & 6734.39 \\
\hline
\end{tabular}

Table 14. TSR/TSC of X City 2013-2018.

\begin{tabular}{ccccccc}
\hline Year & 2013 & 2014 & 2015 & 2016 & 2017 & 2018 \\
\hline TSR/TSC $(\mathrm{T}=0)$ & 0.936 & 0.975 & 0.950 & 0.975 & 1.007 & 0.984 \\
TSR/TSC, $\mathrm{T}=1$, forward & 0.994 & 1.028 & 1.000 & 1.034 & 1.074 & 1.059 \\
TSR/TSC, $\mathrm{T}=$ 2, forward & 1.015 & 1.045 & 1.017 & 1.053 & 1.097 & 1.087 \\
TSR/TSC, $\mathrm{T}=$ 3, forward & 1.017 & 1.045 & 1.019 & 1.054 & 1.100 & 1.094 \\
TSR/TSC, $\mathrm{T}=4$, forward & 1.010 & 1.037 & 1.012 & 1.046 & 1.092 & 1.089 \\
TSR/TSC, $\mathrm{T}=$ 5, forward & 0.998 & 1.024 & 1.000 & 1.033 & 1.079 & 1.078 \\
TSR/TSC, $\mathrm{T}=$ 6, forward & 0.984 & 1.009 & 0.986 & 1.017 & 1.064 & 1.064 \\
TSR/TSC, $\mathrm{T}=$ 7, forward & 0.968 & 0.992 & 0.971 & 1.001 & 1.046 & 1.048 \\
TSR/TSC, $\mathrm{T}=$ 8, forward & 0.952 & 0.976 & 0.955 & 0.984 & 1.029 & 1.032 \\
TSR/TSC, $\mathrm{T}=$ 9, forward & 0.936 & 0.959 & 0.940 & 0.967 & 1.012 & 1.015 \\
TSR/TSC, $\mathrm{T}=10$, forward & 0.921 & 0.943 & 0.924 & 0.950 & 0.995 & 0.999 \\
\hline
\end{tabular}

TSR/TSC: Total Social Revenue/Total Social Cost. 
social revenue and total social cost of $\mathrm{X}$ city in recent years. As shown in Table 14 , the ratio of total social revenue to total social cost of $\mathrm{X}$ city in each year can be obtained from the ratio of total social revenue to total social cost.

According to the above Table 14, we can get the trend chart as shown in Figure 1 .

It can be concluded from Figure 1 that, on the whole, as the years of future implicit revenues and costs are extended, the total social revenue-total social cost ratio of X city, except for 2017, all other years are from less than 1 to greater than 1 and then to less than 1 . This is because in the short term, the increase of total social revenues in $\mathrm{X}$ city is greater than that of total social costs, but in the long term, the increase of total social revenues is gradually slowing down, while the increase of total social costs is gradually increasing. Therefore, the longer the future is considered, the total social cost will gradually exceed the total cost, and the ratio of total social cost to total revenue will gradually be less than 1 . By comparing each year, it can be found that the social revenue/cost ratio of $\mathrm{X}$ city in 2013 is less than 1 when considering the next 5 years. In the recent years of 2017 and 2018, the ratio of social revenue to cost was less than 1 when considering the next 10 years, which is also related to the adjustment of investment structure and the promotion of sustainable development.

Though the above analysis is based on a single area of data analysis, but to a certain extent, it also reflects most of China's local governments have a common problem in decision-making, namely the short-term radical in public decision-making problems. Ignoring the current decision to bring the risk of future (cost) is the important cause of term imbalances.

\subsection{Assessment of the "13 $3^{\text {th }}$ Five-Year Plan"}

Taking the " $13^{\text {th }}$ five year plan" as an example, based on the comprehensive

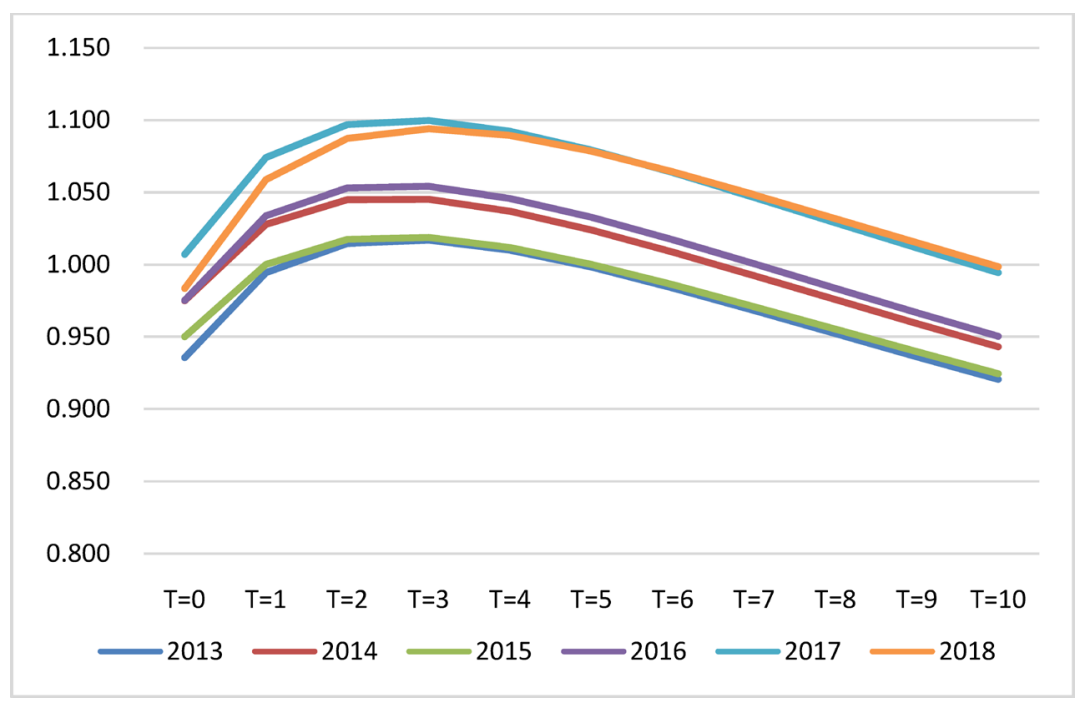

Figure 1. The total social revenue-total social cost ratio of $\mathrm{X}$ city in recent years considering different future risks. 
consideration of national economy, government revenue and expenditure, people's life, ecological environment and natural resources, this part also uses the idea of multidimensional equilibrium and combines with social benefit cost theory to construct the ratio model of the country's total income and total cost in the first three years of the " $13^{\text {th }}$ five year plan". We hope to provide a new perspective for the state to formulate and evaluate the indicators and achievements of the "five-year plan". Referring to the model and accounting method of term equity problem mentioned above, it can be concluded that the country's total income under the condition of implicit income in different future years is considered during the " $13^{\text {th }}$ five-year plan" period, as shown in Table 15.

In the same way, the total loss of the country considering the implicit costs in different future years can be obtained, as shown in Table 16 .

Table 15. The total national revenue considering time in the future (Unit: 100 million yuan).

\begin{tabular}{cc}
\hline $\mathrm{T}^{\text {th }}$ Year in the future & total national revenue \\
\hline $\mathrm{T}=0$ & $631,072.2$ \\
$\mathrm{~T}=1$ & $730,008.3$ \\
$\mathrm{~T}=2$ & $814,745.2$ \\
$\mathrm{~T}=3$ & $887,320.8$ \\
$\mathrm{~T}=4$ & $949,480.5$ \\
$\mathrm{~T}=5$ & $1,002,719$ \\
$\mathrm{~T}=6$ & $1,048,317$ \\
$\mathrm{~T}=7$ & $1,087,371$ \\
$\mathrm{~T}=8$ & $1,120,820$ \\
$\mathrm{~T}=9$ & $1,149,468$ \\
$\mathrm{~T}=10$ & $1,174,005$ \\
\hline
\end{tabular}

Table 16. The total national cost considering time in the future (Unit: 100 million yuan).

\begin{tabular}{cc}
\hline $\mathrm{T}^{\text {th }}$ Year in the future & total national cost \\
\hline $\mathrm{T}=0$ & $685,410.7$ \\
$\mathrm{~T}=1$ & 753,620 \\
$\mathrm{~T}=2$ & $816,776.7$ \\
$\mathrm{~T}=3$ & $875,255.2$ \\
$\mathrm{~T}=4$ & 929,402 \\
$\mathrm{~T}=5$ & $979,537.8$ \\
$\mathrm{~T}=6$ & $1,025,960$ \\
$\mathrm{~T}=7$ & $1,068,943$ \\
$\mathrm{~T}=8$ & $1,108,743$ \\
$\mathrm{~T}=9$ & $1,145,594$ \\
$\mathrm{~T}=10$ & $1,179,716$ \\
\hline
\end{tabular}


Based on Table 15 and Table 16 above, the ratio of total national income to total loss can be obtained by considering the ratio of total national income to total loss in different future years during the $13^{\text {th }}$ five-year period, as shown in $\mathrm{Ta}$ ble 17 .

According to Table 17, we can get the visual bar chart as shown in Figure 2.

Based on the Figure 2, as the number of future years in consideration gradually increases, the ratio of total income and total loss of the country in the $13^{\text {th }}$ five-year period increases first and then decreases, indicating that in the short term, the growth range of implicit income brought by the country's economic activities during the $13^{\text {th }}$ five-year period is greater than the implicit cost. In the long term, the growth range of the implicit income will gradually be smaller than that of the implicit loss, so the ratio of the total income to total loss of the country will gradually decline, and gradually appear less than 1. But from the overall, the much starker choices-and graver consequences-in until $\mathrm{T}=10$, the national total return ratio of the total loss began to appear less than 1, shows that even considering the implicit in the next 10 years or so revenues and costs, the country's total revenue than total loss is only slightly smaller than 1 , close to 1 , shows that countries during much starker choices-and graver consequences-in performance to a certain extent is joint cyber equilibrium state. In general, the formulation and implementation of the $13^{\text {th }}$ plan have maintained economic rationality, given consideration to the present and the future, and achieved remarkable results. It shows that China's economic development during the $13^{\text {th }}$ five-year

Table 17. The ratio of total national revenue to the total national cost.

\begin{tabular}{cccccccccccc}
\hline Year & $\mathrm{T}=0$ & $\mathrm{~T}=1$ & $\mathrm{~T}=2$ & $\mathrm{~T}=3$ & $\mathrm{~T}=4$ & $\mathrm{~T}=5$ & $\mathrm{~T}=6$ & $\mathrm{~T}=7$ & $\mathrm{~T}=8$ & $\mathrm{~T}=9$ & $\mathrm{~T}=10$ \\
\hline the ratio of total national revenue to the total national cost & 0.921 & 0.969 & 0.998 & 1.014 & 1.022 & 1.024 & 1.022 & 1.017 & 1.011 & 1.003 & 0.995
\end{tabular}

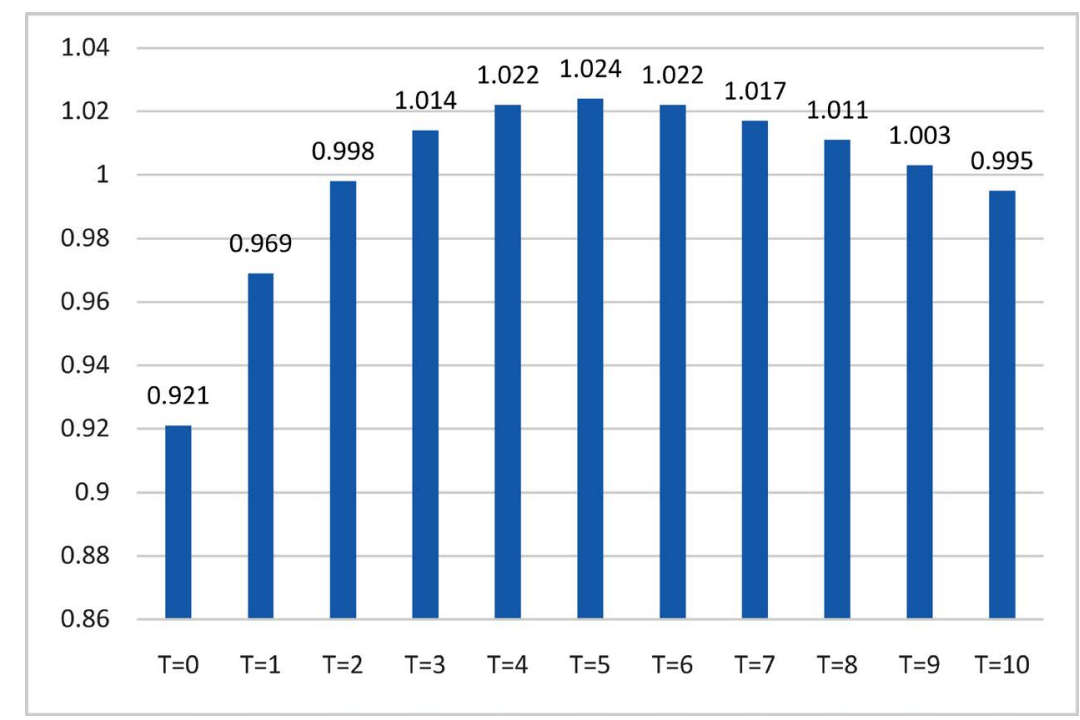

Figure 2. The ratio of national total revenue to total cost during the $13^{\text {th }}$ five-year plan period when considering different future risks. 
period still relies on various dividends to a certain extent, such as system dividend, demographic dividend and resource dividend, etc., which moves the risks of the current period to a certain extent to a longer future.

However, according to the conclusion of this paper and relevant data, it can be found that once the long-term effect (including the implicit loss in the next 10 years or even in the longer term) is included in the assessment of heterogeneous equilibrium, the country's total return gradually fails to cover the total cost. In formulating and implementing the medium and long term development plan, the state still attaches great importance to the current economic development, while the investment in education, education, environmental protection, people's livelihood and other aspects with long-term impact is insufficient. Especially in local development, GDP boom and other phenomena are still widespread. From the perspective of the long-term development of the country and society, the future development plan of the country should give more consideration to the heterogeneous balance, especially the future risk should be included in the plan.

\subsection{Assessment of High-Speed Rail Project}

China's high-speed railway is still in the early stage of development. People tend to pay more attention to various benefits brought by high-speed rail, such as timeliness, environmental protection and driving regional economy, but they often ignore the extra social externality costs caused by the construction of high-speed railway, such as the siphon effect on small and medium-sized cities along the line, which cannot be reflected in finance. It can be seen that only from the financial point of view to explore the cost and income of high-speed rail, and draw the conclusion of high-speed rail profit and cost is somewhat biased. In view of this, this paper takes Beijing Shanghai high-speed railway as an example, discusses the income cost of high-speed railway based on the theory of dissimilarity equilibrium. It is no longer simply from the financial point of view, but fully considers the direct and implicit income and cost caused by the construction of high-speed railway, and analyzes these hidden cost and income which are difficult to be directly quantified. This method provides a new perspective for us to study the impact of high-speed rail on social economy. Similarly, with reference to the model and accounting method of case 1, the ratio of total revenue to total cost of each year can be obtained through the ratio of cumulative total revenue to total cost of Beijing Shanghai high speed railway, as shown in Table 18.

According to Table 18, the following visual bar diagram can be obtained.

Based on Figure 3, with the continuous extension of the years of future implicit costs considered, the total revenue ratio of the Beijing-Shanghai high-speed railway is decreasing, and it is gradually away from the equilibrium point 1 , indicating that the longer the future is considered, the total revenue of the Beijing-Shanghai high-speed railway is less and less able to cover the total 
Table 18. Ratio of total revenue to total cost of Beijing-Shanghai high-speed railway 2012-2018.

\begin{tabular}{ccccccccc}
\hline Year & & 2012 & 2013 & 2014 & 2015 & 2016 & 2017 & 2018 \\
\hline Cumulative total revenue/total cost & $T^{\prime}=0$ & 0.64 & 0.88 & 1.01 & 1.10 & 1.16 & 1.21 & 1.24 \\
Cumulative total revenue/total cost & $T^{\prime}=1$ & 0.46 & 0.69 & 0.84 & 0.94 & 1.02 & 1.08 & 1.13 \\
Cumulative total revenue/total cost & $T^{\prime}=2$ & 0.36 & 0.58 & 0.72 & 0.83 & 0.91 & 0.98 & 1.03 \\
Cumulative total revenue/total cost & $T^{\prime}=3$ & 0.31 & 0.50 & 0.64 & 0.75 & 0.83 & 0.91 & 0.96
\end{tabular}

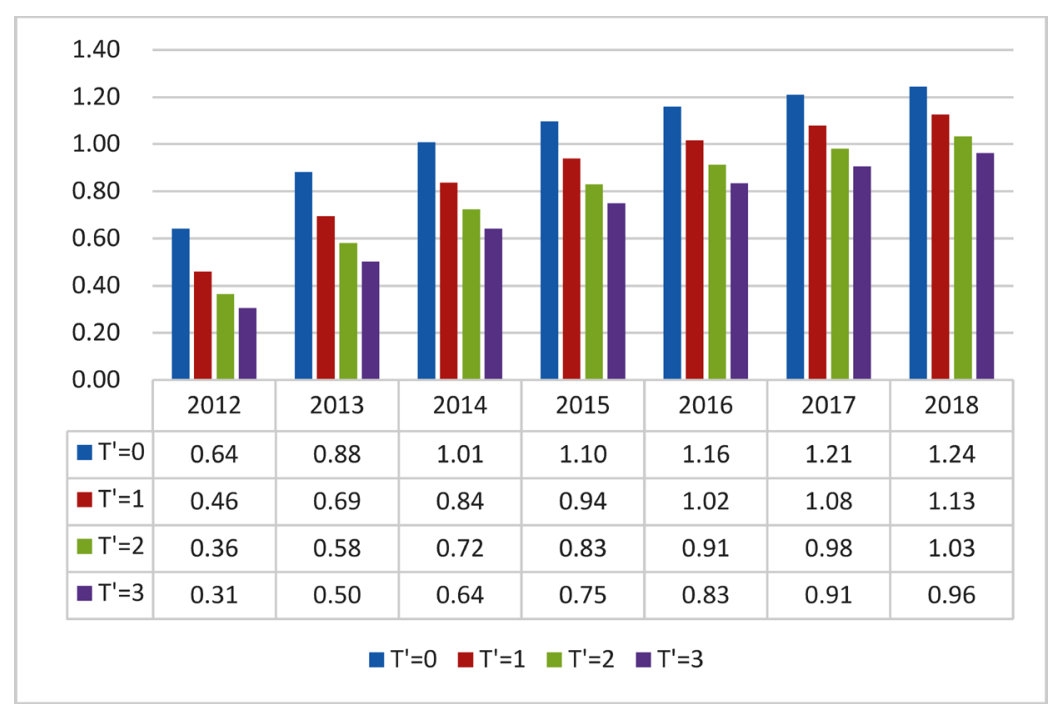

Figure 3. The ratio of total social revenue to total social cost of Beijing-Shanghai high speed railway in recent years.

cost. Only by not considering the future implicit costs or considering only the short-term (1 - 2 years) implicit costs, can the Beijing-Shanghai high-speed railway slightly achieve the total revenue to cover the total costs after years of operation, but this idea of not considering or only considering the short-term future is unscientific and unreasonable, and does not conform to the idea of the theory of multidimensional equilibrium. o, according to the theory of multidimensional equilibrium, consider more long-term future recessive loss, the Beijing-Shanghai high-speed railway projects in the total revenue and total loss ratio is less than 1 , that is, total revenue is unable to cover the total loss, is off the thin equilibrium, and with considering the future of the long term, the extent of the deviation, the more serious (that is, the total revenue is smaller than the total loss is more and more).

Based on the theory of "thin equilibrium of the above conclusion and many scholars from financial accounting only pay to the project income is greater than the cost view is discriminating, thin equilibrium theory not only consider the loss of the paper, more is standing in the dimension of space and time to think about the future of loss and loss of society as a whole range of this theory is more reasonable than the last one only consider financial profit and loss and science, and 
for us to re-examine the human economic activities provides a new perspective.

\section{Conclusion}

The intersection of the future and the past in the present is the basic feature of multidimensional equilibrium. Multidimensional equilibrium theory regard the past, present and future as a consistent overall, which allows us to explain economic phenomena in this framework. Specificly, considering different time space, this paper analyses theoretical principle and scene with unlimited extension, trying to decompose the essence of economic phenomenon deeply and to express the interconnected relations. We not only investigate economic utility, but also involve ethics legal rational justice and other social science philosophy. Multidimensional equilibrium theory is through the surface phenomenon to dig out the implicit truth. Among all kinds of data to establish the concepts about new economic constraints, the modern economic activities, the function and significance of this theory will be more important. This paper describes the direct result of the content and model calculation, which deeply affects every aspect of economic life, and we hope these effects have been presented, and contribute to human civilization.

Although the existing literature has been constantly filling the gap of equilibrium thoughts from multiple angles and dimensions, it still fails to make a comprehensive and unified theory. Based on the research results in history, combined with the economic problems and policy effects in reality, this paper clarifies the connotation of equilibrium and the abnormal nature of equilibrium, and proposes the concept of multidimensional equilibrium on the basis of all the achievements. Finally, we empirically measure the function and function of the theory tool of multidimensional equilibrium in the optimization of policy and sublimation of resource allocation in the light of the prominent economic issues such as the investment decision of Political Term Impartiality in high-speed railway projects and the sustainable development of cities.

This paper constructs a multidimensional equilibrium model to investigate the ratio of total income to total loss of economic activities, and the key of the model is to calculate the total income and total loss of economic activities. In order to incorporate the risk of space-time dimension into the model, this paper divides the income into current and future income, explicit and implicit income, similarly, divides the loss into current and future loss, explicit and implicit loss. However, the methods and parameters used in this paper may not be perfect when calculating the future and implicit income or loss. In the future, we should focus on improving the method to make the calculation of the total income and total loss of economic activities more complete.

\section{Conflicts of Interest}

The authors declare no conflicts of interest regarding the publication of this paper. 


\section{References}

Henry, J. (1983). Mathematical Sciences. The British Journal for the History of Science, $17,232-233$.

Marshall, A. (2006). Principles of Economics: Abridged Edition. New York: Cosimo Classics.

Mill, J. S. (2004). Principles of Political Economy with Some of Their Applications to Social Philosophy. Indianapolis, IN: Hackett Publishing Company.

Murray, M., \& Stimson, S. C. (1996). The Figure of Smith: Dugald Stewart and the Propagation of Smithian Economics. European Journal of the History of Economic Thought, 3, 225-253. https://doi.org/10.1080/10427719600000024

Nash, J. (1950a). Equilibrium Points in N-Person Games. Proceedings of the National Academy of Sciences of the United States of America, 36, 48-49. https://doi.org/10.1073/pnas.36.1.48

Nash, J. (1950b). The Bargaining Problem. Econometrica, 18, 155-162. https://doi.org/10.2307/1907266

Nash, J. (1951). Non-Cooperative Games. Annals of Mathematics, 54, 286-295. https://doi.org/10.2307/1969529

Nash, J. (1953). Two-Person Cooperative Games. Econometrica, 21, 128-140. https://doi.org/10.2307/1906951

Neumann, J. V., \& Morgenstern, O. (1994). Theory of Games and Economic Bebavior. Princeton, NJ: Princeton U Press.

Pang, B. Q., \& Wang, D. Z. (2016). Officials' Tenure System and Economic Performance. China Economic Studies, No. 1, 14-24.

Geng, S., \& Pang, B. Q. (2016). Term of Local Cadres and the Behavior of Local Governments. China Economy Quarterly, 15, 893-916.

Smith, A. (2003). The Wealth of Nations. New York: Bantam Classics.

Walras (1989). Elements of Pure Economics (The Chinese Translation, Trans. Cai Shoubai). Beijing: Commercial Press.

Wang, Y. T. (2018). Enlightenment of Nobel Prize Winner Theory to Green Sustainable Development of China's Economy. Financial Times, No. 4, 10-20.

Xiao, Z. P., \& Duan, N. N. (2008). Who Will Pay Attention to the Tenure of the Chairman? Board of Directors, No. 5, 78-80. 